\section{DESIGN OF A SINGLE-PHASE RADIAL FLUX PERMANENT MAGNET GENERATOR WITH VARIATION OF THE STATOR DIAMETER}

\author{
Hari Prasetijoa*, Winasisa, Priswantoa, Dadan Hermawan ${ }^{b}$ \\ aDepartment of Electrical Engineering, Faculty of Engineering, \\ Jenderal Soedirman University, Purwokerto, Indonesia \\ bDepartment of Chemistry, Faculty of Sciences, Jenderal \\ Soedirman University, Purwokerto, Indonesia
}

Article history

Received

13 June 2018

Received in revised form

11 April 2019

Accepted

16 April 2019

Published online

25 June 2019

*Corresponding author hari.prasetijo@unsoed.ac.id
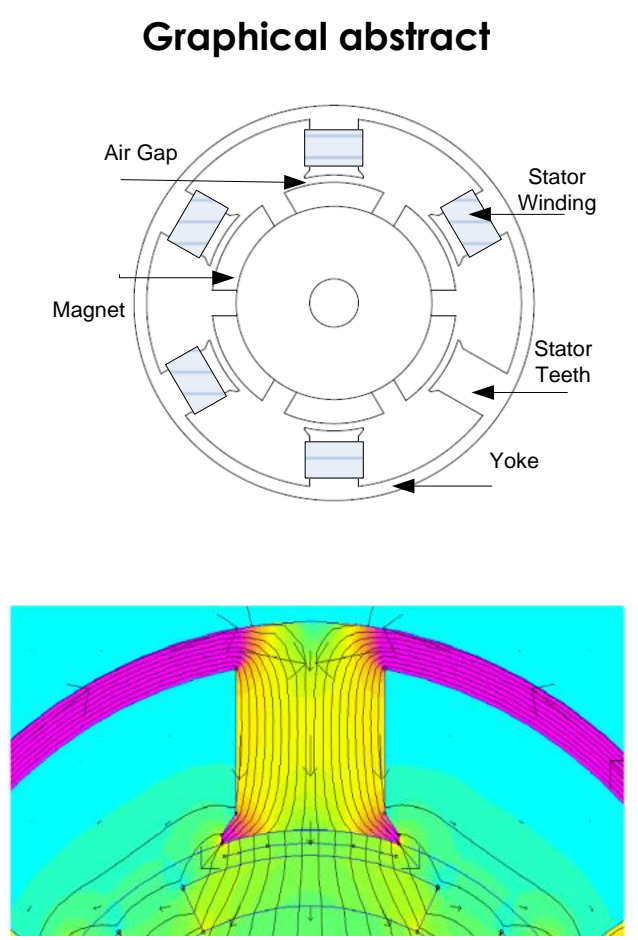

\begin{abstract}
This study aims to observe the influence of the changing stator dimension on the air gap magnetic flux density $\left(B_{g}\right)$ in the design of a single-phase radial flux permanent magnet generator (RFPMG). The changes in stator dimension were carried out by using three different wire diameters as stator wire, namely, AWG $14(\mathrm{~d}=1.63 \mathrm{~mm})$, AWG $15(\mathrm{~d}=1.45 \mathrm{~mm})$ and AWG $16(\mathrm{~d}=1.29 \mathrm{~mm})$. The dimension of the width of the stator teeth $(\mathrm{Wts})$ was fixed such that a larger stator wire diameter will require a larger stator outside diameter ( $\left.D_{s o}\right)$. By fixing the dimensions of the rotor, permanent magnet, air gap (lg) and stator inner diameter, the magnitude of the magnetic flux density in the air gap $\left(B_{g}\right)$ can be determined. This flux density was used to calculate the phase back electromotive force (Eph). The terminal phase voltage $(V \varnothing)$ was determined after calculating the stator wire impedance (Z) with a constant current of 3.63 A. The study method was conducted by determining the design parameters, calculating the design variables, designing the generator dimensions using AutoCad and determining the magnetic flux density using FEMM simulation. The results show that the magnetic flux density in the air gap and the phase back emf Eph slightly decrease with increasing stator dimension because of increasing reluctance. However, the voltage drop is more dominant when the stator coil wire diameter is smaller. Thus, a larger diameter of the stator wire would allow terminal phase voltage $\left(V_{\varnothing}\right)$ to become slightly larger. With a stator wire diameter of $1.29,1.45$ and $1.63 \mathrm{~mm}$, the impedance values of the stator wire (Z) were 9.52746, 9.23581 and $9.06421 \Omega$ and the terminal phase voltages $(V \varnothing)$ were $220.73,221.57$ and $222.80 \mathrm{~V}$, respectively. Increasing the power capacity ( $S$ ) in the RFPMG design by increasing the diameter (d) of the stator wire will cause a significant increase in the percentage of the stator maximum current carrying capacity wire but the decrease in stator wire impedance is not significant. Thus, it will reduce the phase terminal voltage $(\vee \varnothing)$ from its nominal value.
\end{abstract}

Keywords: Permanent magnet generator, radial flux, flux density, voltage, power 


\subsection{INTRODUCTION}

There is significant potential in water energy due to extreme river water flow heads, which are commonly found in mountainous areas. These have been used to power hydropower (5-100 kW) and mini hydro (100 $\mathrm{kW}-1 \mathrm{MW}$ ) systems by utilizing generator technology and conventional turbines. The conventional generator has a high rotation speed ranging from 1500 to $3000 \mathrm{rpm}$. However, if implemented in a low head water catchment area, the turbine-generator spin may not produce the required voltage and nominal power.

Some research focusing on low head turbines has been completed. Erinofiardi et al. [1] conducted an experiment to study a turbine screw coupled with a generator using two pairs of pulley reduction. The experiment used a water debit of $0.00068 \mathrm{~m}^{3} / \mathrm{s}$, with the generator spinning at a speed of $560 \mathrm{rpm}$ and a turbine with a speed of $232 \mathrm{rpm}$ producing a current of $33.1 \mathrm{~mA}$ with a voltage of $2.97 \mathrm{~V}$. In the second pulley, the generator spun at $2457 \mathrm{rpm}$ and the turbine with a speed of $946 \mathrm{rpm}$ produced a current of 61.6 $\mathrm{mA}$ with a voltage of $4.5 \mathrm{~V}$. Split reaction water turbines have potential applications for low micro hydro head installations. This turbine has mechanical and electrical efficiency in the range of $65-70 \%$ [2].

Compared to doubly-fed induction generators, Permanen Magnet sinkron generator (PMSG) has a higher efficiency and simpler structure because it has a permanent magnet instead of field winding in the rotor [3]. It is easier to change pole numbers in order to obtain the nominal rotational speed of the generator. One important aspect in the design of a permanent magnet generator is the flux density surrounding the stator coil [4]. The magnetic flux assembly of the stator coil $\left(\mathrm{B}_{g}\right)$ determines the output voltage and the power of the permanent magnet generator. The larger the magnetic flux density, the greater the output voltage and generator power [5]. Sharma et al. [6] argued that a permanent magnet generator has the ability to withstand the inrush current into the system when the system is connected to a synchronous input. In addition, permanent magnet synchronous generators also have advantages, such as no brush loss, no separate DC source for excitation, easy maintenance and the ability to protect themselves against overload and short-circuit [7]. Testing on a prototype of a threephase axial double-sided permanent magnet generator can be done using 16 magnets on each rotor. Magnetostatic and magnetodynamic analyzes are performed with the finite element method using $250 \mathrm{~W}$ of power and a $5 \mathrm{~mm}$ air gap.

Conventional generators are operated using excitation systems, while for permanent magnet generators under load conditions, there is a decrease in magnetic flux (demagnetization) due to flux from the stator current generated by a fixed magnet [8]. However, in permanent magnet generators, there is no loss of brush power or power on the rotor. With a low air gap, the stator current becomes so small until the power loss on the stator can be neglected. This means that permanent magnet generators have high efficiency $[9,10]$. In addition, the size and weight of the permanent magnet generator are smaller than the conventional generator because it does not require an excitation system [11].

Related to the study and development of a permanent magnet generator, Irasari [12] compared the characteristics of barium ferrite magnets $\left(\mathrm{BaF}_{12} \mathrm{O}_{19}\right)$ with neodymium iron boron (NdFeB). From their results, the flux of $\mathrm{NdFeB}$ was ten times larger than $\mathrm{BaF}_{12} \mathrm{O}_{19}$. NdFeB also has the best price-to-power ratio compared to SmCo, ferrite and AINiCo [13]. Herudin and Prasetyo [14] designed a permanent magnetic flux generator that produced $\sim 7.91 \mathrm{~V}$. At load conditions, the generator generated a voltage of 6.11 $\checkmark$ with an efficiency of $32.84 \%$. This performance needs to be reviewed for improvement. Ahmed and Ahmad [15] innovated the design using MATLAB Simulink to increase the efficiency of the axial permanent magnet generator that is applied to wind power plants. This method creates the characteristics of a permanent magnet generator in the construction process. Prasetijo and Waluyo [16] designed a ten poles single-phase axial permanent magnetic generator, type double-sided coreless stator, which resulted in a voltage of $87.25 \mathrm{~V}$ with a power of 322.84 $V A$. The output voltage of the generator is still lower than the nominal voltage of the electrical apparatus if it is implemented as a generator in a pico hydropower generating system.

This study will contribute to the process of designing a single-phase radial flux permanent magnet generator (RFPMG). The purpose of this study is to obtain the design of a single-phase RFPMG with a terminal voltage generator of $220 \mathrm{~V}$, output power of $800 \mathrm{VA}$ and a frequency of $50 \mathrm{~Hz}$. The observed variables are the diameter of the stator winding wire, the voltage and output power of the generator. The analysis was performed using FEMM 4.2 to obtain the value of the magnetic flux density in the air gap.

Compared to findings from Herudin and Prasetyo [14] and Prasetijo and Waluyo [16], there are some developments that can be observed. The first study calculated the voltage drop on the stator winding to determine the value of the induction voltage $(E)$ and the terminal voltage of the generator (V). Secondly, the resulting terminal voltage reached a nominal phase voltage of $220 \mathrm{~V}$ according to the nominal value of the low voltage network of PT.PLN. Thirdly, the magnetic flux density $\left(B_{g}\right)$, magnetic flux $(\varnothing)$, electric motion $\left(E_{p h}\right)$, terminal phase voltage generator $\left(V_{\varnothing}\right)$ and power $(S)$ of three types of stator winding wire size were compared.

Figure 1 shows the rotor-stator of a RFPMG. An air gap is a distance between the magnet and the stator bore. The magnet is a flux generating magnet located on the rotor. Stator tooth is the stator part of the entanglement. There are six magnetic poles used to obtain a rotor speed of $1000 \mathrm{rpm}$ at a frequency of 50 $\mathrm{Hz}$. The yoke is the outer stator thickness. 


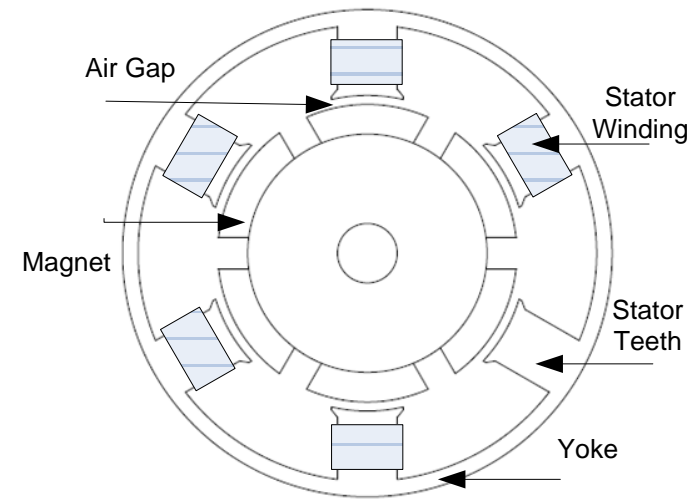

Figure 1 Permanent magnet generator of radial flux

\subsection{METHODOLOGY}

The stages and flow of the study activities are shown in Figure 2. It can be seen that the study is initiated by determining parameter values, calculating variable RFPMG dimensions, generator drawing construction in Autocad and 2D finite element analysis in FEMM.

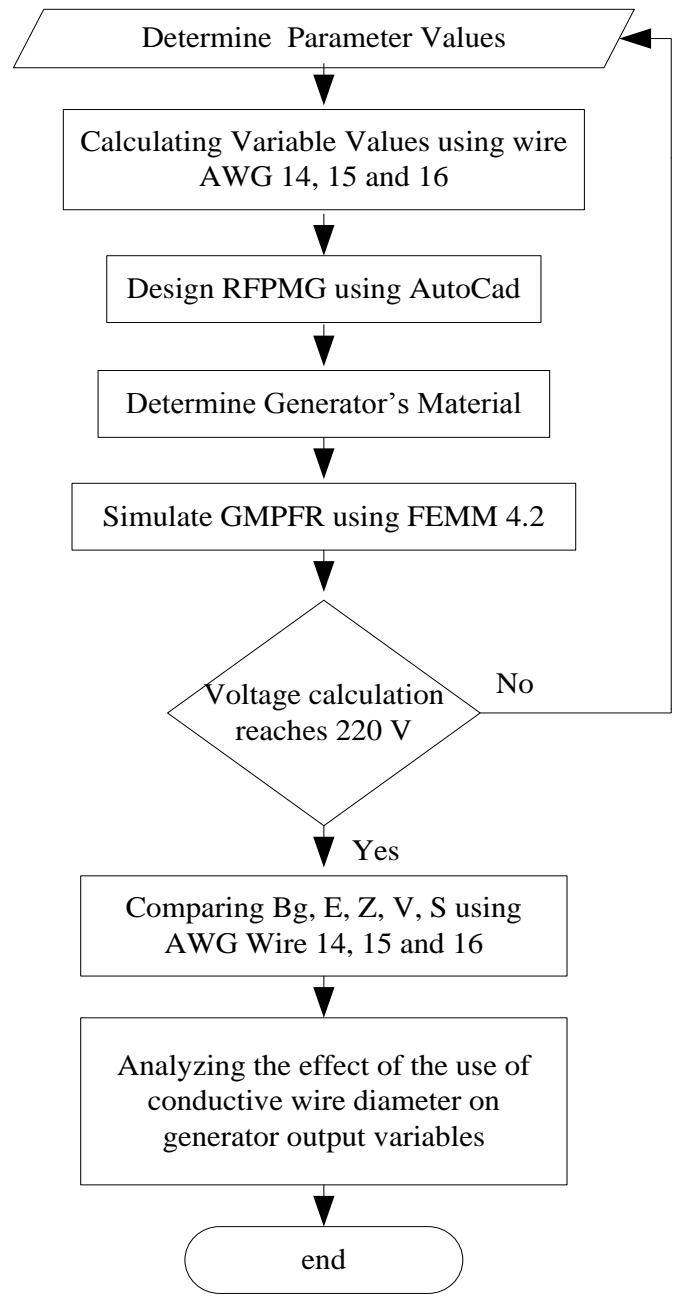

Figure 2 Flowchart of study steps

\subsection{Radial Flux Permanent Magnet Generator Dimensions and Parameters}

In the determination of the size of each part of the generator, the required input parameters are directly determined so that they can assist in the process of making the other parts of the generator. The following parameters influence the design of a permanent magnet synchronous generator of a single phase flux, as can be seen in Table 1.

Table 1 Permanent magnet generator dimensions and parameters

\begin{tabular}{ccc}
\hline Parameters & Data & Unit \\
\hline Frequency, $\mathrm{f}$ & 50 & $\mathrm{~Hz}$ \\
\hline Speed, $\mathrm{n}$ & 1000 & $\mathrm{Rpm}$ \\
\hline Rotor Inner Diameter, $\mathrm{D}_{\mathrm{ri}}$ & 0.08 & $\mathrm{~m}$ \\
\hline Magnet Thickness, $\mathrm{t}_{\mathrm{m}}$ & 0.01 & $\mathrm{~m}$ \\
\hline Air Gap, $\mathrm{I}_{\mathrm{g}}$ & 0.003 & $\mathrm{~m}$ \\
\hline Rotor Axial Length, $\mathrm{L}$ & 0.08 & $\mathrm{~m}$ \\
\hline Stator tooth Width, $\mathrm{W}_{\mathrm{ts}}$ & 0.02 & $\mathrm{~m}$ \\
\hline
\end{tabular}

\subsection{Designing Generator Design Variables}

\subsubsection{Rotor}

Th rotor of the RFPMG is a magnetic field generator because the permanent magnet is placed on the rotor part. Figure 3 shows the rotor dimensions of the RFPMG. The type of magnet used in this study is NdFeB (neodymium-iron-boron). The determination of variables for the rotor design includes:

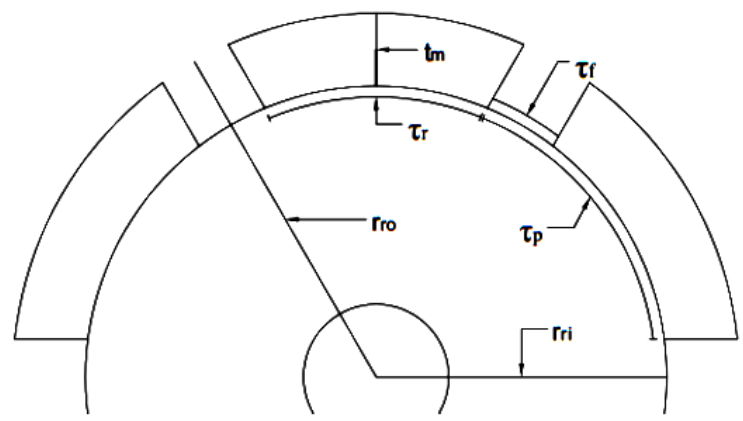

Figure 3 GSMFR rotor dimensions.

\section{A. Number of Generator Poles ( $p$ )}

There is a relationship between frequency and speed in determining the number of poles in the synchronous generator. The number of poles can be determined using equation (1).

$$
f=\frac{n p}{120}
$$

where:

$\mathrm{f}=$ frequency $(\mathrm{Hz})$

$\mathrm{n}=$ rotational speed of the rotor (rpm)

$\mathrm{p}=$ number of magnetic poles 


\section{B. Rotor and Stator Pole Ranges}

The rotor pole range $(T)$ is the actual magnet span, while the stator pole range $(T)$ is the circumferential length of the magnetic pole can and be calculated using equations (2) and ( 3 ) below:

$$
\begin{gathered}
\tau_{p}=\frac{\left(\pi \times \mathrm{D}_{\mathrm{ri}}\right)}{\mathrm{p}} \\
\tau_{r}=\tau_{m}=\tau_{p} \times 0.75
\end{gathered}
$$

\section{Distance Between Magnets $(\tau f)$}

Determining the distance between magnets can refer to equation (4) by using previously known variables:

$$
\tau_{f}=\tau_{p}-\tau_{r}
$$

\section{Permeance Coefficient (PC)}

The following equations are used to determine the value of the PC:

$$
\begin{gathered}
P_{C}=\frac{\mathrm{t}_{\mathrm{m}}}{\left(\lg _{\mathrm{g}} \mathrm{l} \emptyset\right)} \\
C_{\varnothing}=\frac{A_{m}}{A_{g}}=\frac{2 \alpha_{\mathrm{m}}}{\left(1+\alpha_{\mathrm{m}}\right)} \\
\alpha_{\mathrm{m}}=\frac{\tau_{m}}{\tau_{p}}
\end{gathered}
$$

where:

$t_{m}=$ magnet thickness $(\mathrm{m})$

$C_{\varnothing}=$ factor of flux concentration

$A_{m}=$ magnitude of the area facing the stator

$A_{g}=$ constant area of air gap

\section{E. Effective Length and Area of Rotor Pole}

Equations (8) and (9) are used to calculate the effective core length value $(L i)$ and the area of the rotor pole $(A p r)$ :

$$
\begin{gathered}
L_{i}=L_{i} K_{\text {stack }} \\
A_{p r}=\tau_{\mathrm{r}} L_{i}
\end{gathered}
$$

\section{F. Outer Diameter of Rotor}

Equation (10) can be used to determine the outside diameter of the rotor:

$$
D_{r o}=2 \times t_{m}+D_{r i}
$$

\subsubsection{Stator}

The stator itself is part of a generator that is usually static. Figure 4 shows the stator variables and its dimensions. The determination of variable stator design includes:

\section{A. Inner Diameter Stator}

The inner diameter of the stator is determined by adding the air gap width to the outer diameter of the rotor, as displayed in equation (11):

$$
D_{s i}=2 \times l_{g}+D_{r o}
$$

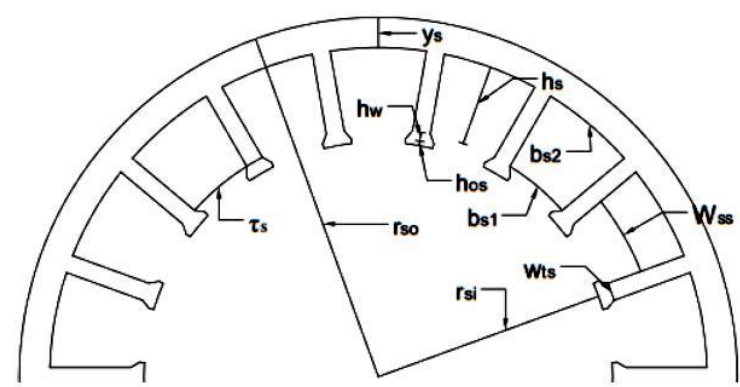

Figure 4 Stator GSMPFR specification

\section{B. Number of Slots}

The number of slots on the stator can be calculated using equation (12):

$$
S_{s}=p \cdot q . m
$$

The number of slots in one phase $\left(S_{f}\right)$ and the number of slots that can be magnetized by a single pole (Sk) can be determined using equations (13) and (14):

$$
\begin{gathered}
S_{f}=\frac{S_{s}}{\mathrm{~m}} \\
S_{k}=\frac{S_{s}}{\mathrm{k}}
\end{gathered}
$$

\section{Inner Slot Width (bsi)}

Based on Figure 3, bsl is the radial length of the inner slot area. Therefore, the value of bsl can be determined using equation (15):

$$
b_{s 1}=\frac{\left(\pi\left(\mathrm{D}_{\mathrm{si}}+2 \mathrm{~h}_{\mathrm{os}}+2 \mathrm{~h}_{\mathrm{w}}\right)\right)}{\mathrm{s}_{\mathrm{s}}}-\mathrm{W}_{\mathrm{ts}}
$$

\section{Area of Stator Slot}

Before determining the area of the stator slot, it is important to determine the type of wire used in this study because it will affect the value of the conductor diameter (equations (16)-(19)):

$$
\begin{gathered}
A_{s s}=\frac{\left(\mathrm{A}_{\mathrm{w}} \mathrm{N}_{\mathrm{s}}\right)}{\mathrm{F}_{\mathrm{F}}} \\
\mathrm{A}_{\mathrm{W}}=\frac{\mathrm{I}_{\mathrm{ph}}}{\mathrm{J}} \\
d_{w}=\sqrt{\frac{\left(4 . \mathrm{A}_{\mathrm{w}}\right)}{\pi}} \\
J=\frac{\mathrm{I}_{\mathrm{max}}}{\mathrm{A}_{\mathrm{w}}}
\end{gathered}
$$

E. Width of Outside of Stator Slot (bs2)

After bs 1 is obtained, it can determine the value of bs2, which is the radial length of the outer slot area (equation (20)):

$$
b_{s 2}=\sqrt{\frac{4 A_{s s} \tan \pi}{S_{s}}+b_{s 1}^{2}}
$$




\section{F. Stator Slot Height}

After the above equation is known, it can then determine the height of the stator slot by using equation (21):

$$
h_{s}=\frac{2 A_{s s}}{b_{s 1}+b_{s 2}}
$$

G. Middle Value of Radial Length of Stator Slot (Wss) $W_{s s}$ is the value that will be used to calculate the value of $k_{c}$ in the determination of the value $B g$. The value of $W_{S S}$ itself is calculated using equation (22) as follows:

$$
W_{s s}=\frac{b_{s 1}+b_{s 2}}{2}
$$

\section{H. Long Range of Stator Slot Area}

The range for the length of the stator slot area (Ts) is the sum of the length $b s 1$ and length $W t s$ (equation (23)):

$$
\tau_{s}=b_{s 1}+W_{t s}
$$

I. Value of Flux Density $\left(B_{g}\right)$ in Generator

The flux density value $(\mathrm{Bg})$ can be determined after the leakage value $(\mathrm{kml})$ and the Carter coefficient $(\mathrm{kc})$, which are calculated as follows:

a. Determining Leakage Value $\left(\mathrm{km}_{\mathrm{m}}\right)$

The value of $\mathrm{kml}$ be calculated using equation (24):

$$
k_{m l}=1+\frac{4 t_{m}}{\pi \mu_{r} \cdot \alpha_{m} \cdot \tau_{p}} \ln \left[1+\frac{\pi l_{g}}{\left(\left(1-\alpha_{m}\right) \tau_{p}\right)}\right]
$$

\section{b. Carter Coefficient ( $k c)$}

In the determination of the value of $k_{c}, l g$ is an unknown parameter. The value of $l g$ ' is the effective air gap length, which can be calculated using equations (25) and (26):

$$
\begin{gathered}
l_{g}{ }^{\prime}=l_{g}+\frac{\mathrm{t}_{\mathrm{m}}}{\mu_{\mathrm{r}}} \\
k_{c}=\left[1-\frac{W_{s s}}{\tau_{\mathrm{s}}}+\frac{4 l_{g}{ }^{\prime}}{\pi \tau_{\mathrm{s}}} \ln \left(1+\frac{W_{s s} \pi}{4 l_{g}{ }^{\prime}}\right)\right]-1
\end{gathered}
$$

\section{c. Value of $\mathrm{Bg}$}

The magnetic flux density, $\mathrm{Bg}$ can be calculated using equation (27):

$$
B_{g}=\frac{\left(C_{\emptyset}\right)}{\left(1+\frac{\mu_{\mathrm{r}} \cdot \mathrm{k}_{\mathrm{c}} \cdot \mathrm{k}_{\mathrm{ml}}}{\mathrm{P}_{\mathrm{C}}}\right)} \mathrm{Br}
$$

\section{J. Distribution Factor}

The value of the distribution factor can be calculated using equations (28)-(30):

$$
\begin{aligned}
& \beta=\frac{180}{S_{S} \cdot \mathrm{m}} \\
& c=\frac{S_{s}}{\mathrm{p} \cdot \mathrm{m}}
\end{aligned}
$$

$$
k_{d}=\frac{\sin (\mathrm{c} \cdot \beta / 2)}{\mathrm{c} \cdot(\sin \beta / 2)}
$$

\section{K. Magnetic Flux Value}

Equation (31) can be used to determine the magnetic flux value:

$$
\emptyset=B_{g} A_{p r}
$$

where Apr is the magnetic surface area.

L. Width of Yoke Stator (YS) and Stator Outside Diameter ( $\left.D_{s 0}\right)$

The yoke stator is a buffer of stator construction or is often called the stator frame. The stator yoke can be calculated using equations (32) and (33):

$$
\begin{gathered}
Y_{s}=\frac{\emptyset}{2 \cdot L_{i} \cdot B_{t s}} \\
D_{s 0}=D_{s i}+2\left(h_{s}+h_{0 s}+h_{w}+Y_{s}\right)
\end{gathered}
$$

\subsection{Determination of Electricity Variables of Generator Output}

The determination of electricity variables of generator output includes:

\section{A. Phase Back Emf (Eph) Generator Valve}

The value of Eph is represented during open-circuit conditions. Equation (34) can be used to calculate Eph:

$$
E_{p h}=4,44 \times f \times N_{s} \times k_{w} \times S_{f} \times \emptyset
$$

\section{B. Phase Current lph and Phase Resistance (Rph)}

The Iph and Rph values are used to determine the output voltage of the generator. Equations (35) and (36) can be used to calculate Iph and Rph:

$$
\begin{gathered}
I_{p h}=A_{w} J \\
R_{p h}=\frac{\rho_{\mathrm{w}} \times N_{s} \times \mathrm{L}_{\mathrm{c}}}{A_{w}} \frac{S_{S}}{\mathrm{~m}}
\end{gathered}
$$

\section{Reactance and Impedance Valve Generator}

The reactance value in the generator can be calculated using equation (37). Once the resistance and reactance values are obtained, the value of the generator impedance can be computed using equation (38):

$$
\begin{aligned}
& X_{L}=4 . m \cdot \mu_{o} \cdot f \frac{\left(N_{s} \cdot k_{w}\right)^{2}}{\pi p^{\prime}} \frac{S_{k} \cdot L_{i}}{K_{c} \cdot l_{g}} \\
& \mathrm{Zph}=Z_{p h}=\sqrt{R_{p h}{ }^{2}+X_{L}{ }^{2}}
\end{aligned}
$$


D. Phase Voltage Output Value

The output voltage value can be computed using the following formula:

$$
\mathrm{V}_{\varnothing}=\mathrm{E}_{\mathrm{ph}}-\mathrm{I}_{\mathrm{ph}} \mathrm{R}_{\mathrm{ph}}
$$

\section{E. Output Power Generator}

The output power refers to the apparent power that is generated by the multiplication of voltage and electric current. Equation (40) is used to determine the apparent power:

$$
S=V \times I
$$

\subsection{RESULTS OF SIMULATION AND DISCUSSION}

In this study, there are several developments compared to Herudin [13] and Prasetijo [15]. The first study was to calculate the voltage drop on the stator winding so that it can determine the value of the phase back emf (Eph) and the terminal phase voltage of the generator $(V \varnothing)$. Second, the resulting terminal voltage reached a nominal phase voltage of $220 \mathrm{~V}$ according to the nominal value of the low voltage network of PT. PLN. Third, the values of magnetic flux density $\left(B_{g}\right)$, magnetic flux $(\varnothing)$, phase back emf $\left(E_{p h}\right)$, terminal voltage generator $\left(V_{\varnothing}\right)$ and power $(S)$ for three types of stator winding wire size were calculated and compared.

The generator design uses three wire sizes by referring to the American Wire Gauge (AWG), namely, AWG 14, AWG 15 and AWG 16, which were equivalent to wire diameters of $1.63,1.45$ and $1.29 \mathrm{~mm}$, respectively, as stator windings. By increasing the size of the wire in the stator winding, the generator power output capacity was greater due to the increased in the current capacity that can be passed through the stator coil as an armature coil by producing the back emf on the generator. This affected the stator dimension. The type of wire conductor did not affect the size of the rotor dimension but affected the stator dimension of the generator. Table 2 shows the dimensions of a permanent magnetic flux generator using the three wires as a stator coil. These dimensions were derived from the calculations using the equations in the sub methodology.

From Table 2, it can be seen that an increment in the power capacity ( $S$ ) of the generator resulted by increasing the diameter of the stator coil wire had an impact on the several stator dimensions, i.e., the outer diameter of the stator $\left(D_{s o}\right)$, the height of the stator teeth (hs) and the length of the outer stator slot (bs2).

\begin{tabular}{|c|c|c|c|}
\hline \multirow{2}{*}{ Parameter } & \multicolumn{3}{|c|}{ Dimension (m) } \\
\hline & AWG 14 & AWG 15 & AWG 16 \\
\hline$D$ & 0.02 & 0.02 & 0.02 \\
\hline Dri & 0.08 & 0.08 & 0.08 \\
\hline Dro & 0.1 & 0.1 & 0.1 \\
\hline$\tau p$ & 0.04187 & 0.04187 & 0.04187 \\
\hline$\pi r$ & 0.0314 & 0.0314 & 0.0314 \\
\hline$\tau f$ & 0.01047 & 0.01047 & 0.01047 \\
\hline$T m$ & 0.01 & 0.01 & 0.01 \\
\hline $\operatorname{Lg}$ & 0.003 & 0.003 & 0.003 \\
\hline$L$ & 0.08 & 0.08 & 0.08 \\
\hline $\mathrm{Li}$ & 0.072 & 0.072 & 0.072 \\
\hline$D_{s i}$ & 0.106 & 0.106 & 0.106 \\
\hline Dso & 0.16706 & 0.15882 & 0.15228 \\
\hline Wts & 0.02 & 0.02 & 0.02 \\
\hline$h_{s}$ & 0.02239 & 0.01815 & 0.01478 \\
\hline$\tau_{S}$ & 0.05861 & 0.05861 & 0.05861 \\
\hline bsl & 0.03861 & 0.03861 & 0.03861 \\
\hline bs2 & 0.06447 & 0.05958 & 0.05568 \\
\hline \multirow{2}{*}{ hos, hw } & 0.001 & 0.001 & \multirow{2}{*}{0.0010 .002} \\
\hline & 0.002 & 0.002 & \\
\hline$Y_{S}$ & 0.00514 & 0.00526 & 0.00536 \\
\hline
\end{tabular}

Table 2 GMPFR design dimensions with stator coil variation.

With fixed magnetic flux ( $\varnothing$ ) and back emf (Eph), an increment in the power capacity of the RFPMG is to increase the outer diameter of the stator (Dso).

Figure 5 shows a description of the design dimension of the permanent magnetic flux generator from Table 2. The inner part is the rotor dimension while the outer part is the stator dimension. The permanent magnet acts as a magnetic flux generator that lies in the rotor portion instead of the field coil. Between the stator teeth and permanent magnet is an air gap (lg). 


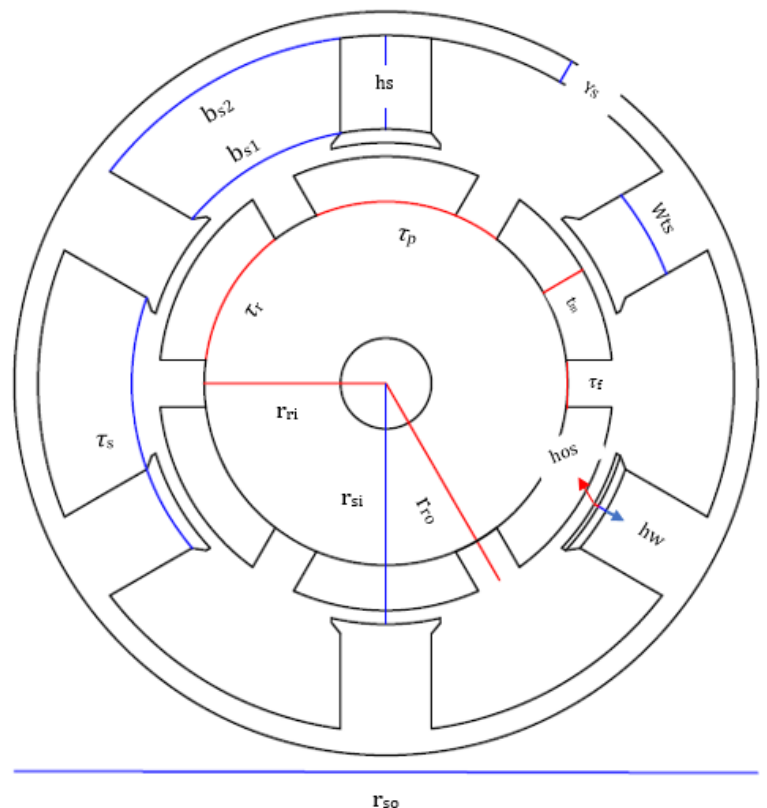

Figure 5 Design dimensions of RFPMG

\subsection{Finite Element Simulation and Analysis}

This simulation and analysis were achieved by using FEMM software to determine the magnetic flux $\left(B_{g}\right)$ density of the air gap. The design dimension of the RFPMG was used as a simulation base with the following steps.

\section{A. Design in FEMM Software}

To obtain the magnetic flux $\left(B_{g}\right)$ density in the air gap, the generator design was illustrated in the FEMM software by labeling the material of each component of the generator. The selected materials can be seen in Table 3.

Table 3 Material description of each component

\begin{tabular}{cc}
\hline Generator Components & Materials \\
\hline Rotor Shaft & Mild Steel \\
\hline Rotor & Aluminum 1100 \\
\hline Permanent Magnet & NdFeB 32 MgOe \\
\hline Stator & M-19 Steel \\
\hline
\end{tabular}

Aluminum was chosen because it has a very strong mechanical alloy that can reduce thermal conductivity and its resistance to corrosion. Silicon steel has a steel content that can reduce eddy current and reduce hysteresis core lamination.

\section{B. Meshing Design on FEMM Software}

The next stage was the prototype meshing using FEMM software. Meshing is a tool to define the boundaries of the materials defined in the design. The material boundary of each component was limited using yellow webs (mesh). The image meshing design is displayed in Figure 6.

\section{Simulation of Magnetic Flux in Air Gap}

The simulations were performed on three generator designs: each using AWG 14, AWG 15 and AWG 16 wires of 160 loops per slot to keep the back emf (Eph) relatively fixed.

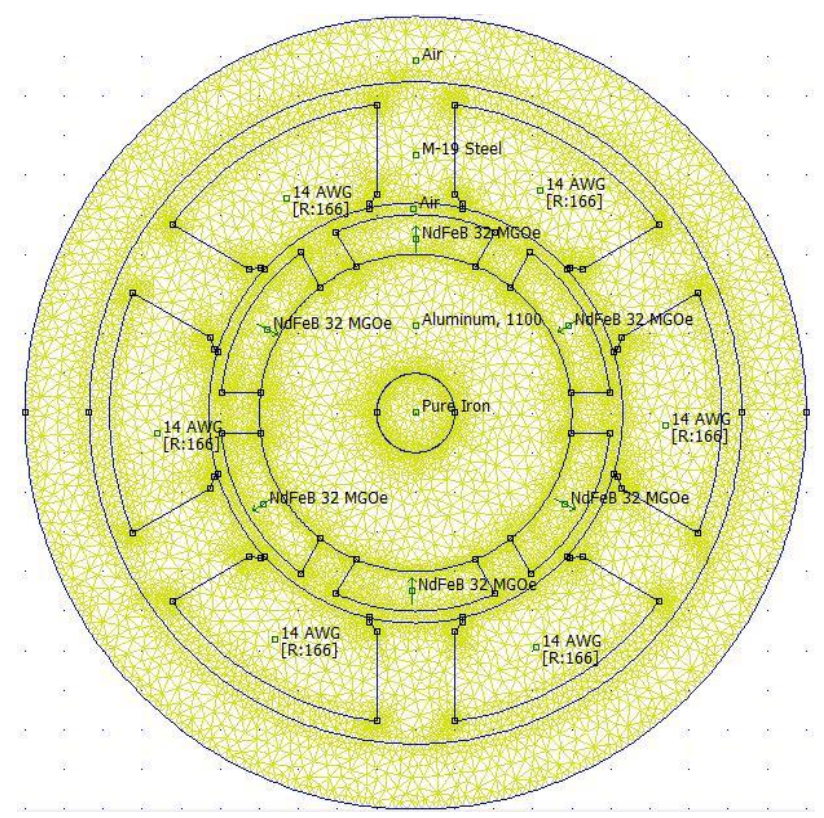

Figure 6 Meshing RFPMG design on FEMM

Figure 7 shows the simulation results of the design of the RFPMG. The color contour shows the magnitude of the magnetic flux density by the order of magnetic flux density levels from small to large: blue, green, yellow, orange and purple. The lowest flux is in the air (blue) while the highest is in the yoke stator (purple) because the yoke stator is made of silicon steel that has higher permeability. Magnetic permeability is the ability of a material to pass a magnetic force line based on equation (41).

$$
\mu=\mu_{o} \cdot \mu_{r}
$$

where:

$$
\begin{aligned}
& \mu=\text { permeability } \\
& \mu_{o}=\text { permeability vacuum, } \\
& 3.14 \times 10^{-7} \mathrm{~Wb} / \mathrm{A} . \mathrm{m} \\
& \mu_{r}=\text { relative permeability of materials }
\end{aligned}
$$

The relative permeability of silicon steel has a value of 1500 times that of air. Thus, it can be used to explain the magnetic flux density of the yoke, which was larger than the flux density in the air gap region. 
The stator teeth exhibit an orange color, showing that the level of the magnetic flux density was lower than the yoke. This was due to the back emf on the stator coil induced flux in the direction against the flux of the permanent magnet.

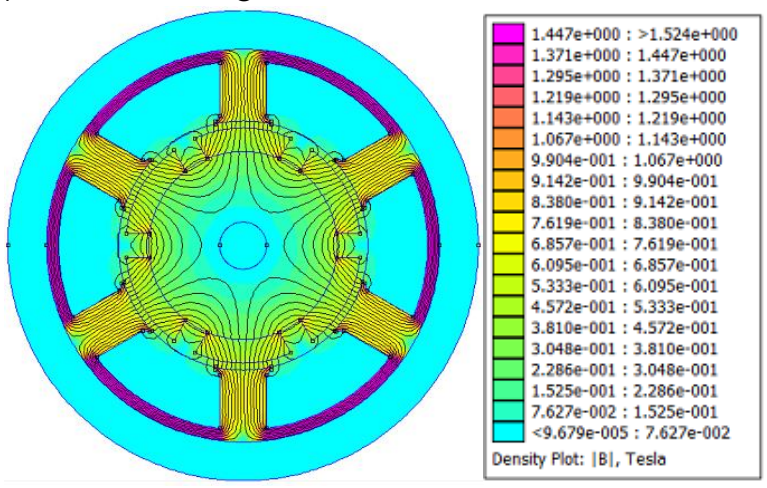

Figure 7 Simulation of magnetic flux density generator design

Flux in the air gap between the magnetic pole and the stator pole (stator teeth) was required for the calculation of the back emf (Eph) on the stator coil. To find the flux, five test points along the air gap under the stator pole were taken. Figure 8 shows the test point for finding the magnetic flux density $\left(B_{g}\right)$.

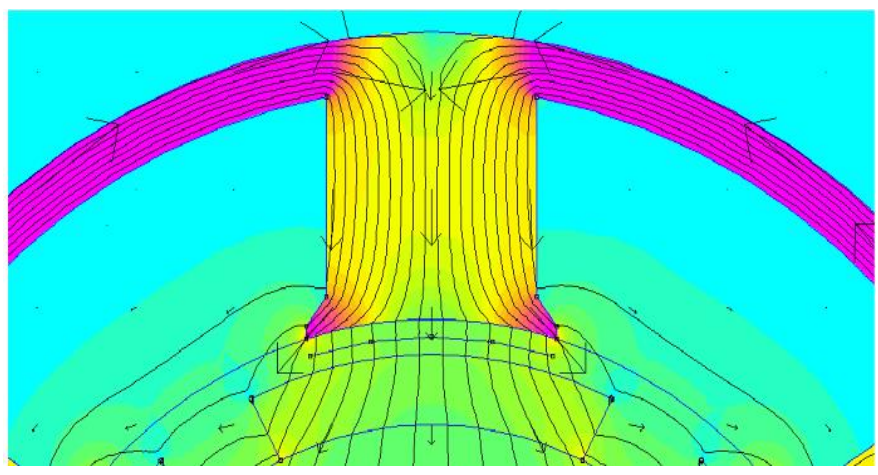

Figure 8 Simulation of magnetic flux density with five test points in the air gap

Figure 8 also shows that the flux density in the stator teeth (stator coil location) is smaller than the density of the yoke flux. This is because the induced voltage produces the opposite flux from the direction of permanent magnetic flux, as shown in equation (42):

$$
e=-\frac{d \varphi}{d t}
$$

\section{Simulation of Single-Phase RFPMG Design with AWG Wire 14}

Using the above steps, the magnetic flux density $(B g)$ in the single-phase RFPMG design air gap with the stator coil using the AWG 14 wire was determined. The results are shown in Figure 9 with test points 1 to 5 being the points on the air gap (can refer to Figure 8 from left to right).

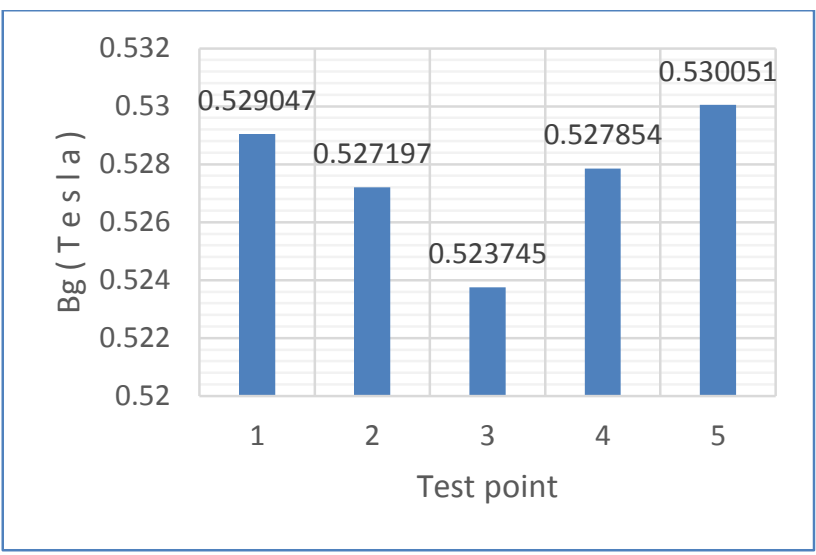

Figure 9 Graph of GSMPFR testing with AWG 14

The value of the coordinates of the test point used and the resulting flux density value can be seen in Table 4. The $B_{g}$ value at five test points located under the stator pole (stator teeth) has a value between 0.5 and $0.6 \mathrm{~T}$.

Table 4 Air gap test point with AWG 14

\begin{tabular}{cl}
\hline Test point & Nilai Bg $(T)$ \\
\hline 1 & 0.529047 \\
\hline 2 & 0.527197 \\
\hline 3 & 0.523745 \\
\hline 4 & 0.527854 \\
\hline 5 & 0.530051
\end{tabular}

The $B_{g}$ value is determined from the average $B_{g}$ value in the five test points of $0.52958 \mathrm{~T}$.

Figure 10 shows the waveform of the air gap flux density distribution from one side middle magnet pole adjacent to the other side (pole-pitch) that show a $1 / 2$ period waveform.

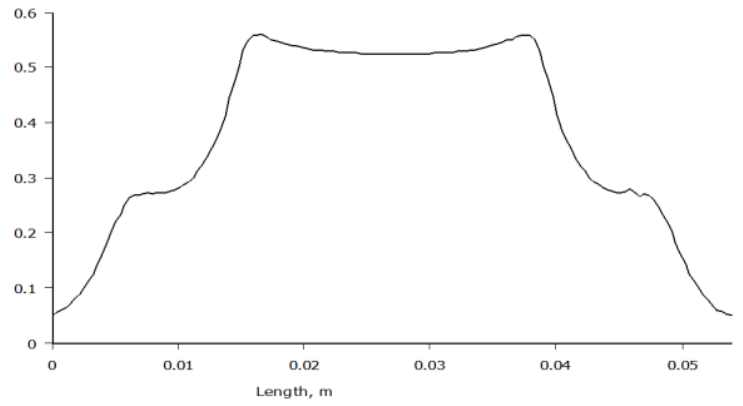

Figure 10 Waveform of air gap flux density distribution 


\subsection{RFPMG Output Variable Calculation}

The RFPMG output variables include phase back emf $\left(E_{p h}\right)$, phase current $\left(I_{p h}\right)$, phase voltage $\left(V_{\emptyset}\right)$ and output power (S). The calculation of RFPMG output variables is achieved with the following steps.

\section{A. Determining Phase Back Emf (Eph)}

The predetermined $\mathrm{Bg}$ value through the simulation was used to calculate the $\emptyset$ flux and phase back emf (Eph) using equation (34).

$$
\begin{aligned}
& \emptyset=\mathrm{B}_{\mathrm{g}} \cdot \mathrm{A}_{\mathrm{pr}}=0.52918 \times 0.00226=0.001196 \mathrm{~Wb} \\
& E_{p h}=4.44 \times 50 \times 160 \times 1 \times 6 \times 0.001196=254.89 \mathrm{~V}
\end{aligned}
$$

Figure 11 show the induced voltage (back-emf) as a sinusoidal waveform.

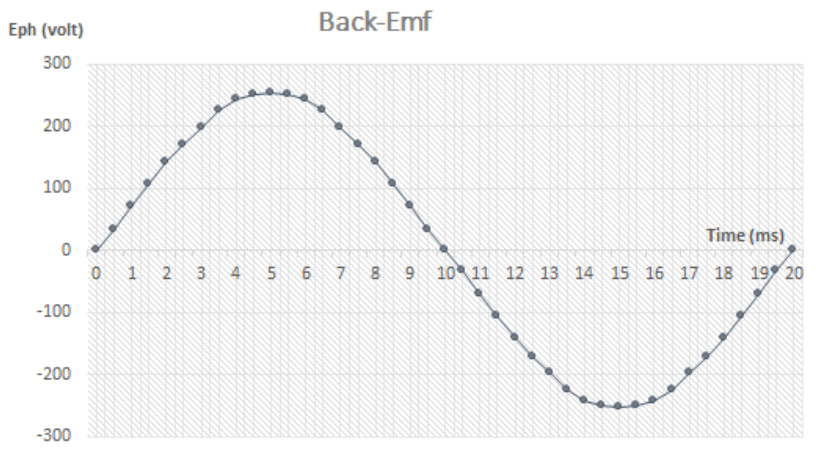

Figure 11 Back-Emf waveform

\section{B. Determining lph and Rph Generator}

The phase current value (Iph) was used to find the maximum current value generated from the conducting wire using equation (35).

$I_{p h}=A_{w} . J=2.08567 \times 10^{-6} \times 2828831.93454=5,9 \mathrm{~A}$

where $A_{w}$ is the wire cross-sectional area of AWG 14 in units of $\mathrm{m}^{2}$ (wire diameter AWG $14=1.29 \mathrm{~mm}$ ) and $\mathrm{J}$ is the current density of AWG 14 in units of $A / \mathrm{m}^{2}$.

Since in this study, the generator output was limited to a $220 \mathrm{~V}$ output voltage and $800 \mathrm{VA}$ output power, the current used to achieve the generator output value can be calculated by the equation below:

$$
\begin{gathered}
I_{p h}=\frac{S}{V}=\frac{800}{220}=3.63 \mathrm{~A} \\
\% I_{\text {max }}=\frac{3.63}{5.9}=61.52542 \%
\end{gathered}
$$

The desired value of per phase current was equal to $3.63 \mathrm{~A}$ or $61.52542 \%$ from the maximum current value of the AWG 14 wire. The per phase resistance $(R p h)$ was used to find the impedance value of the generator output using equation (36).

$$
R_{p h}=\frac{\rho_{w} \times N_{s} \times L_{c}}{A_{w}} \frac{S_{s}}{m}
$$

where $\rho_{w}$ is density type of mass $(\Omega \cdot m), N_{s}$ is the number of turns, $L_{c}$ is the length of one winding $(m)$, Ss is the number of stator slots and $m$ is the number of phases. The value of the stator coil resistance is:

$$
R_{p h}=\frac{1.72 E^{-08} \times 166 \times(2 \times(0.02+0.072))}{2.08567 E^{-08}} \frac{6}{1}=1.51134 \mathrm{Ohm}
$$

\section{Determining Reactance Valve and Impedance Generator}

Before determining the output impedance value of the generator, the value of reactance $\left(X_{L}\right)$ was calculated using equation (37).

$$
X_{L}=4 . m . \mu_{o} . f \frac{\left(N_{s} \times k_{w}\right)^{2}}{\pi p^{\prime}} \frac{s_{k} \times L_{i}}{K_{c} \times l_{g}}
$$

where $\mathrm{m}$ is the number of phases, $\mathrm{K}_{\mathrm{w}}$ is the winding factor, which is the ratio between the coil dimension and the stator slot dimension, $p$ is the number of pairs of stator curves, Sk is he slot per pole, $L i$ is the effective length of the rotor, $K_{c}$ is Carter's coefficient, i.e., per long ratio slot stator with air gap width and $\mathrm{lg}$ is the air gap width. Thus, the value of stator coil reactance can be computed by the following equation:

$$
X_{L}=4 \times 1 \times 4 \times 3.14 \times 10^{-7} \times 50 \frac{(160 \times 1)^{2}}{3,14 \times 3} \frac{1 \times 0.072}{1,91056 \times 0.003}=
$$$$
8.9373 \Omega
$$

By knowing the value of resistance and stator coil reactance, the output impedance of the generator was calculated using equation (38).

$$
Z_{p h}=\sqrt{{R_{p h}{ }^{2}+X_{L}^{2}}^{2}}=\sqrt{1.51134^{2}+8.93732^{2}}=9.06421 \Omega
$$

\section{Determining the Output Phase Voltage}

After obtaining the value of the back emf (Eph), the phase current (Iph), the phase impedance (Zph) and the value of the output terminal phase voltage generator $\left(V_{\emptyset}\right)$ can be calculated by subtracting the back emf value by the voltage drop on the stator coil using equation (39).

$$
V \varnothing=E_{p h}-I_{p h} . Z_{\mathrm{ph}}=255.74-(3.63 \times 9.06421)=222.8 \mathrm{~V}
$$

\section{E. Determining Generator Output Power}

The final step was to determine the output power of the generator by multiplying the output voltage of the generator with the phase current obtained. Below is the calculation to find the output power generator with equation (40).

$S=V \times I=222.8 \mathrm{~V} \times 3.63=808.8 \mathrm{~V}$ 
By performing the same calculation procedure for stator wind types AWG 15 and AWG 16, the comparison of variable values was made and summarized, as shown in Table 5.

From Table 5, it is known that the magnetic flux $\left(B_{g}\right)$ tends to slightly decrease sequentially from the use of the AWG $16(\mathrm{~d}=1.29 \mathrm{~mm})$, AWG $15(\mathrm{~d}=1.45 \mathrm{~mm})$ and AWG $14(\mathrm{~d}=1.63 \mathrm{~mm})$ wires. The larger the diameter of the wire in the stator coil with the same rotor and magnetic dimensions, the smaller the flux density and the magnetic flux. By referring to Figure 5 on the design parameters and Table 2, the larger the diameter of the wire on the stator coil, the larger the stator height (hs). As the height of the stator teeth (hs) increases, the length of the outer stator slot (bs2) also increases in size. By increasing the size of $b_{s} 2$, with reference to equation (22), the size of the middle length of the radial slot stator ( $W_{s s}$ ) also increases. Based on equation (26), the coefficient of the charter $\left(K_{c}\right)$ increases if the $W_{s s}$ value increases. The relationship between these variables can be explained clearly using equation (27):

$$
B_{g}=\frac{\left(\mathrm{C}_{\varnothing}\right)}{\left(1+\frac{\left.\mu_{\mathrm{r}} \times \mathrm{k}_{\mathrm{c}} \times \mathrm{k}_{\mathrm{ml}}\right)}{\mathrm{P}_{\mathrm{C}}}\right)} \mathrm{B}_{\mathrm{r}}
$$

From equation (27), the other parameters were fixed. The concentration factor $\left(C_{\varnothing}\right)$ of equation (6) was determined by the surface area of the magnet facing the stator $\left(A_{m}\right)$ and the air gap width constant $\left(A_{g}\right)$. In the design of the magnetic dimension and air gap, the values of $A m$ and $A g$ remained so that the value of $C_{\varnothing}$ also remained. The $\mu_{r}$ parameter is the relative permeability of a NdFeB N32 magnet (1.1). The $\mathrm{kml}$ parameter is a magnetic flux leakage variable based on equation (24), whereby its value was influenced by the rotor and magnetic dimensions. Because the dimensions of the rotor and magnet were fixed, then the $\mathrm{kml}$ value was also fixed. From equation (5), the value of the PC (permeance coefficient constant) was influenced by the magnet thickness (tm) and air gap width ( $/ g)$, whereas both were fixed so that the $P_{C}$ value was also fixed. The parameter $\mathrm{Br}$ was the magnetic flux density of the NdFeB N32 magnet. The $B r$ value is 1.

Another explanation can be reached from the concept of reluctance. The longer the material, the greater the reluctance, as shown below:

$$
\mathcal{R}=\frac{\ell}{\mu A}
$$

where:

$$
\begin{aligned}
& \mathcal{R}=\text { reluctance } \\
& \mu=\text { permeability } \\
& A=\text { cross-sectional area }
\end{aligned}
$$

The greater the stator outside diameter (Dso), the greater the reluctance increase that causes the magnetic flux decrease.
Table 5 Comparison of generator parameters

\begin{tabular}{cccc}
\hline \multirow{2}{*}{$\begin{array}{c}\text { Para } \\
\text { meters }\end{array}$} & $\begin{array}{c}\text { AWG 16 } \\
(\mathrm{d}=1.29 \\
\mathrm{mm})\end{array}$ & $\begin{array}{c}\text { AWG 15 } \\
(\mathrm{d}=1.45 \\
\mathrm{mm})\end{array}$ & $\begin{array}{c}\text { AWG } 14 \\
(\mathrm{~d}=1.63 \\
\mathrm{mm})\end{array}$ \\
\hline Bg & $0.52995 \mathrm{~T}$ & $0.52961 \mathrm{~T}$ & $0.52958 \mathrm{~T}$ \\
\hline$\varnothing$ & $0.001198 \mathrm{~Wb}$ & $0.001197 \mathrm{~Wb}$ & $0.001196 \mathrm{~Wb}$ \\
\hline Eph & $255.32 \mathrm{~V}$ & $255.10 \mathrm{~V}$ & $254.89 \mathrm{~V}$ \\
\hline $\mathrm{Z}$ & $9.53 \Omega$ & $9.24 \Omega$ & $9.06 \Omega$ \\
\hline I & $3.63 \mathrm{~A}$ & $3.63 \mathrm{~A}$ & $3.63 \mathrm{~A}$ \\
\hline V & $220.73 \mathrm{~V}$ & $221.57 \mathrm{~V}$ & $222.80 \mathrm{~V}$ \\
\hline S & $801.30 \mathrm{VA}$ & $804.30 \mathrm{VA}$ & $808.80 \mathrm{VA}$ \\
\hline V_drop & $34.59 \mathrm{~V}$ & $33.53 \mathrm{~V}$ & $32.09 \mathrm{~V}$ \\
\hline $\begin{array}{c}\text { Maximum } \\
\text { Current }\end{array}$ & $3.70 \mathrm{~A}$ & $4.70 \mathrm{~A}$ & $5.90 \mathrm{~A}$ \\
\hline
\end{tabular}

From Table 5, it is also known that when the dimensions of the coil wire increased, the back emf (Eph) on the stator coil also decreased, but the generator terminal voltage was increased. In accordance with equation (39), the smaller the diameter of the stator coil wires, the greater the stator coil impedance. This caused the voltage drops across the stator coil to be greater, so that the terminal voltage becomes smaller. Thus, the decrease in back emf (Eph) of the stator coil was smaller than the drop in voltage $(\Delta V)$ on the stator coil. The larger the diameter of the stator coil wire, the larger the terminal voltage $(\vee \varnothing)$.

By referring to Table 5 and the discussion above, the relation of the stator wire diameter $(d)$, the stator wire impedance (Z), the maximum current carrying capacity (I) and the voltage drop on the AWG wires 16,15 and 14 can be determined, as shown in Table 6 .

Table 6 shows that the increase in wire diameter from AWG 16 to 15 (1.29 to $1.45 \mathrm{~mm}$ ) and from AWG 15 to 14 ( 1.45 to $1.63 \mathrm{~mm}$ ) will cause changes, namely, an increase in the maximum current carrying capacity, a decrease in wire impedance and an increase in maximum voltage drop. The percentage changes can be seen in Table 7 .

From Table 6, it is known that increasing the diameter (d) of the stator wire will increase the maximum carrying capacity (I), thereby increasing the RFPMG power capacity (S). 
Table 6 Comparison derivative variables of AWG 16, 15 and 14

\begin{tabular}{cccc}
\hline & AWG 16 & AWG 15 & AWG 14 \\
\hline Diameter (mm) & 1.29 & 1.45 & 1.63 \\
\hline $\begin{array}{c}\text { Maximum } \\
\text { Current (A) }\end{array}$ & 3.70 & 4.70 & 5.90 \\
\hline $\begin{array}{c}\text { Z Stator Wire } \\
\text { (Ohm) }\end{array}$ & 9.53 & 9.24 & 9.06 \\
\hline $\begin{array}{c}\text { Maximum } \\
\text { Voltage Drop } \\
\text { (V) }\end{array}$ & 35.25 & 43.41 & 53.48 \\
\hline
\end{tabular}

Table 7 Percentage changes in parameters

\begin{tabular}{ccc}
\hline & AWG 16 to 15 & AWG 15 to 14 \\
\hline $\begin{array}{c}\text { Increase in } \\
\text { diameter (\%) }\end{array}$ & 12.40 & 12.41 \\
\hline $\begin{array}{c}\text { Increase in maximum } \\
\text { current (\%) }\end{array}$ & 27.03 & 25.53 \\
\hline $\begin{array}{c}\text { Decrease in } \\
\text { impedance (\%) }\end{array}$ & 3.06 & 1.86 \\
\hline $\begin{array}{c}\text { Increase in voltage } \\
\text { drop (\%) }\end{array}$ & 23.14 & 23.20 \\
\hline
\end{tabular}

Based on Table 7, increasing the power capacity $(S)$ in the RFPMG design by increasing the diameter (d) of the stator wire with a constant value in the phase back emf $\left(E_{p h}\right)$ variable, the dimensions of the rotor, permanent magnet, air gap $(l g)$ and inner diameter stator must be paid attention to the voltage drop $(\Delta \mathrm{V})$ of the stator wire to obtain the nominal value of the phase terminal voltage.

Increasing the diameter of the stator wire will cause a significant increase in the percentage of the stator maximum current carrying capacity wire but the decrease in stator wire impedance is not significant. For the examples of Tables 6 and 7 , an increase in the stator wire diameter from AWG $16(d=1.29 \mathrm{~mm})$ to AWG $15(d=1.45 \mathrm{~mm}$ ) increases the maximum current carrying capacity of $27.03 \%$, but the impedance reduction is only $3.06 \%$. This will cause an increase in voltage drop $(\Delta \mathrm{V})$ of $23.14 \%$, so that it will reduce the phase terminal voltage $(V \varnothing)$ from its nominal value.

\subsection{CONCLUSION}

In design of single-phase radial flux permanent magnet generator, the wire dimensions of the stator coil affected the dimensions of the stator's outer diameter $\left(D_{s i}\right)$, the height of the stator gear $\left(h_{s}\right)$, the length of the outer stator slot $\left(b_{s 2}\right)$ and the yoke width of the stator $\left(Y_{s}\right)$. The increment in the dimension of the outer diameter of the stator $\left(D_{s i}\right)$ due to the larger diameter of the stator coil wire by constant values of the dimensions of the rotor, permanent magnet, air gap $\left(l_{g}\right)$, stator height $\left(h_{s}\right)$ and stator diameter $\left(D_{s i}\right)$, causing magnetic flux density $\left(B_{g}\right)$ and the magnetic flux $(\varphi)$ in the air gap tends to decrease the value, so that value of the back emf $\left(E_{p h}\right)$ decreased too. However, as the diameter of the stator coil wire decreased, value of drop voltage $(\Delta \mathrm{V})$ became significant, so terminal voltage (VT) increased with the larger diameter of the stator coil wire. From the result of simulation and discussions proved that the stator wire with diameters of $1.29 \mathrm{~mm}$ (AWG 16), $1.45 \mathrm{~mm}$ (AWG 15) and $1.63 \mathrm{~mm}$ (AWG 14) had air gap fluxes $\left(B_{g}\right)$ of $0.52995,0.52961$ and $0.52958 \mathrm{~T}$ that produced terminal voltages of 220.73, 221.57 and $222.80 \mathrm{~V}$, respectively. Another result, increasing the power capacity $(S)$ in the RFPMG design by increasing the diameter $(d)$ of the stator wire will cause a significant increase in the percentage of the stator maximum current carrying capacity wire but the decrease in stator wire impedance is not significant. So that it will reduce the phase terminal voltage $\left(V_{\varnothing}\right)$ from its nominal value.

\section{References}

[1] Erinofiardi, Syaiful, M., Prayitno, A. 2015. Electric Power Generation from Low Head Simple Turbine for Remote Area Power Supply. Jurnal Teknologi. 74(5): 21-25.

[2] Date, A., Akbarzadeh, A., Alam, F. 2012. Examining the Potential of Split Reaction Water Turbine for Ultra-Low Head Hydro Resources. Procedia Engineering. 49: 197-204.

[3] Jin-Hyung Yoo, Chang-Seok Park, Tae-Uk Jung. Permanent Magnet Structure Optimization for Cogging Torque Reduction of Outer Rotor Type Radial Flux Permanent Magnet Generator. IEEE International Electric Machines and Drives Conference (IEMDC) 2017.

[4] Prasetijo, H. 2013. Prototype Permanent Magnetic Generator Axial AC 3 Phase As Pico Hydro Power Generating Components. Proceedings of the National Seminar on Rural Resource Development and Local Wisdom III. Part IV. Unsoed. Purwokerto 2013. 26-37.

[5] Kasim, dkk. 2011. Analysis of the Effect of Air Pass Flux Meeting on Permanent Magnet Generator Characteristics. Journal of Electricity and Renewable Energy. 10: 123-130.

[6] Sharma Pawan, T. S. Bhatti, dan K. S. S. Ramakrishnan. 2011. Permanent-magnet Induction Generators. New Delhi: Indian Institute of Technology Delhi.

[7] Gor, H., Kurt,E. 2015. Preliminary Studies of New Permanen Magnet Generator with the Axial and Radial Flux Morphology. International Journal of Hydrogen Energy. 41 (17): 7005-7018.

[8] Faiz, J., Valipour, Z., Kojouri, S. M. 2016. Design of a Radial Flux Permanent Magnet Wind Generator with Low Coercive Force Magnets. 2016 2nd International Conference on Intelligent Energy and Power Systems (IEPS). Kiev, Ukraine. IEEE Xplore. 28 July 2016.

[9] Reljic, D., Corba, Z., Dumnic, B. 2010. Application of Permanen Magnet Synchronous Generator within SmallScale Hydropower System. Journal on Processing and Energy in Agriculture.14(3): 149-152.

[10] Zhang, X., Du, Q., Ma, C., Ma, S., Xu, J., Geng, H., Tian, G. 2016. Ne-Fe-B Permanen Magnet Generator and Voltage Stabilizing Control Technology for Vehicles. Advance in Mechanical Engineering. 8(9): 1-11.

[11] Dutta, R., Rahman, F. 2005. Interior Permanen Magnet Generator: Generator of New Millenium. International Energy Journal. 6(1): 51-57.

[12] Irasari, P. 2012. Simulation and Magnetic Analysis of Permanent Magnetic Permanent Flux Generator 
Generator Using Finite Element Method. Mechatronics, Electrical Power, and Vehicular Technology. 3: 23-30.

[13] Kallaste, A., Vaimann, T., Belahcen, A. 2017. Influence of Magnet Material Selection on the Design of Slow-Speed Permanent Magnet Synchronous Generators for Wind Applications. Elektronika IR Elektrotechnika. 23(1): 31-38.

[14] Herudin dan Wahyu Dwi Prasetyo. 2016. Synchronous Generator Build 1 Permanent Magnetic Phase Low Speed 750 RPM. Scientific Journal of Strum UNTIRTA. 11-15.
[15] Ahmed, D., Ahmad, A. 2013. An Optimal Design of Coreless Direct-drive Axial Flux Permanent Magnet Generator for Wind Turbine. 6th Vacuum and Surface Sciences Conference of Asia and Australia (VASSCAA-6).

[16] Prasetijo, H., Waluyo, S. 2015. Optimization of Air-gap Rotorstator Width Without Nucleus Axial Magnet Permanent Low Phase 1 Phase using FEMM 4.2. Journal of National Electrical Engineering and Information Technology UGM. 4(4): 2015. 